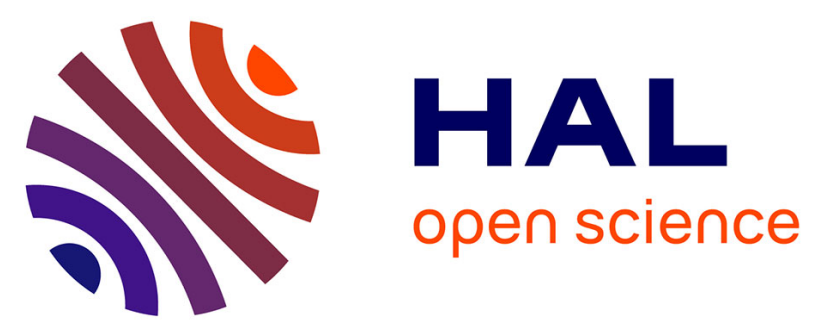

\title{
Amorphous Hydrogenated Silicon Nitride Deposited by Mercury Photosensitization Chemical Vapour Deposition for Optoelectronic Applications
}

\author{
P. Pastorino, G. Morello, S. Tamagno
}

\section{- To cite this version:}

P. Pastorino, G. Morello, S. Tamagno. Amorphous Hydrogenated Silicon Nitride Deposited by Mercury Photosensitization Chemical Vapour Deposition for Optoelectronic Applications. Journal de Physique IV Proceedings, 1995, 05 (C5), pp.C5-1149-C5-1155. 10.1051/jphyscol:19955136 . jpa00253833

\section{HAL Id: jpa-00253833 \\ https://hal.science/jpa-00253833}

Submitted on 1 Jan 1995

HAL is a multi-disciplinary open access archive for the deposit and dissemination of scientific research documents, whether they are published or not. The documents may come from teaching and research institutions in France or abroad, or from public or private research centers.
L'archive ouverte pluridisciplinaire HAL, est destinée au dépôt et à la diffusion de documents scientifiques de niveau recherche, publiés ou non, émanant des établissements d'enseignement et de recherche français ou étrangers, des laboratoires publics ou privés. 


\title{
Amorphous Hydrogenated Silicon Nitride Deposited by Mercury Photosensitization Chemical Vapour Deposition for Optoelectronic Applications
}

\author{
P. Pastorino, G. Morello and S. Tamagno \\ Centro Studi e Laboratori Telecomunicazioni, via Reiss Romoli 274, 10148 Torino, Italy
}

\begin{abstract}
In this work we focus on the properties of anorphous hydrogenated silicon nitride (a-SiN:H) films deposited by mercury sensitization Photo-Chemical Vapour Deposition (Photo-CVD) utilizing SiH4 and $\mathrm{NH}_{3}$ and their suitability for the realization of III-V semiconductor optoelectronic devices (dielectric insulation, protection of reverse junctions, process mask, selective regrowth, antireflection coating).

Using proper deposition conditions we have obtained a-SiN:H films with breakdown field of $8.9 \mathrm{MV} / \mathrm{cm}$, good spatial uniformity of the dielectric properties, refractive index of 1.85 at $1.535 \mathrm{~nm}$, quasi-stoichiometric composition $(\mathrm{Si} / \mathrm{N}=0.8)$, energy gap of $4.22 \mathrm{eV}$ and density of $2.51 \mathrm{~g} / \mathrm{cm}^{3}$, absence of pores and bubbles. We can reproduce film thickness, refractive index and energy gap within $\pm 3 \%, \pm 0.005$ and $0.05 \mathrm{eV}$ respectively.

SiN/InP structures similar to the actual optoelectronic devices have been employed in order to test mechanical adhesion and thickness of the a-SiN:H film grown on vertical facets.

A-SiN:H films deposited in the optimized conditions have been successfully used in the previously mentioned applications.
\end{abstract}

\section{INTRODUCTION}

Amorphous hydrogenated silicon nitride (a-SiN:H) films deposited by various techniques are used for several applications in the electronic and optoelectronic devices technology (interlayer insulation, device passivation, mechanical protection) [1-7].

In this work we are particularly interested in a-SiN:H films deposited by mercury sensitization PhotoChemical Vapour Deposition (Photo-CVD) for their application in some step process of the realization of optoelectronic devices based on the III-V semiconductor system (dielectric insulation, protection of modulators junction, process mask, antireflection coating in optical amplifiers and lasers).

To these aims, some critical aspects exist. In order to minimize the current leakage, a-SiN $: \mathrm{H}$ films are requested first of all to have high dielectric strength and resistivity. In addition, the adhesion between dielectric/semiconductor and metalization/dielectric layers must be very good, the InP/a-SiN $: H / T i P t A u$ sequence must show a good resistance to the thermal and mechanical treatments occurring during the device processing such as diffusion and ohmicization for the ohmic contact realization, chip cleaving, pside down or up chip mounting, wedge or ball-bolding soldering. Besides Photo-CVD a-SiN:H films are particularly suitable for the protection of reverse junctions because of the low mechanical damage induced on III-V semiconductor surfaces. At last we verified that the film thickness deposited on vertical and horizontal surfaces is the same; this fact, in addition to the good control on the refractive index of the films allows us to obtain anti-reflective coatings with rellectivity of $\approx 10^{-2}$.

While optical, electrical and structural properties and applications of a-SiN:H films deposited with plasma techniques have been widely investigated, at our knowledge very few literature exists which reports studies based on Photo-CVD a-SiN:H films.

In this work we report on the properties of our a-SiN:H films that we have optimized in order to successfully use the tilms in some step process of optoelectronic devices technology. 


\section{EXPERIMENTAL}

\subsection{Deposition apparatus}

A-SiN $\mathrm{X}: \mathrm{H}$ films have been deposited in a TYLAN PVD- 1000 equipment by using $\mathrm{SiH}_{4}$ and $\mathrm{NH}_{3}$ pure gases. In the mercury sensitization Photo-CVD, mercury atoms excited by the $253.7 \mathrm{~nm}$ resonance line transfer thier energy by collision to silane and ammonia molecules, generating their free radicals as well known in literature [8]. Secondary ion mass spectrometry investigations of mercury sensitized nitride deposition did not give any evidence of the presence of mercury atoms in the films [9]. From deepdepletion transient-capacitance measurements was found that the use of mercury vapours does not seem to result in any lifetime degradation [10].

The original deposition apparatus has been modilied in order to improve the reproducibility of film properties. We installed a close-loop pressure control to maintain a constant value in the deposition chamber and a single Low Pressure Mercury Vapour Grid Lamp (power density $45 \mathrm{~W} / \mathrm{m}^{2}$, emission wavelength $253.7 \mathrm{~nm}$ ) instead of the original six with the intention of getting the highest optical power spatial uniformity.

Several samples have been deposited varying the $\mathrm{NH}_{3} / \mathrm{SiH}_{4}$ gas flow ratio (R) from 25 to 200 and the total flow rate $(F)$ from 52 to $201 \mathrm{sccm}$. Two temperature values have been investigated $\left(\mathrm{T}_{1}=200^{\circ} \mathrm{C}\right.$, $\mathrm{T}_{2}=250^{\circ} \mathrm{C} ; \mathrm{T}_{2}$ is the maximum allowed value of the deposition machine). Deposition time ( $\mathrm{t}$ ) has been changed from 5 to 360 minutes in order to obtain the desired film thickness. Pressure (p) and optical power density $(\mathrm{P})$ have been kept constant to $1000 \mathrm{~m}$ Torr and $4.5 \mathrm{~mW} / \mathrm{cm}^{2}$ respectively. With respect to our applications the optimized deposition parameters have been chosen to be: pressure ( $p=1000 \mathrm{mTorr})$, temperature $\left(\mathrm{T}=250^{\circ} \mathrm{C}\right), \mathrm{NH}_{3} / \mathrm{SiH}_{4}(\mathrm{R}=100)$ total tlow rate $(\mathrm{F}=101 \mathrm{sccm})$.

In spite of the suggestion of the deposition system supplier, we observed that the use of Fomblin oil on the quartz window of the chamber results in an high incorporation of oxygen (up to $30 \%$ at.) and carbon (up to $20 \%$ at.) in the films determined by using Secondary Neutral Mass Spectroscopy (SNMS) analysis; we therefore decided to eliminate this contamination source obtaining pure silicon nitride (with oxygen and carbon percentages less than SNMS sensitivity) to the detriment of the growth rate.

To achieve uniformity and reproducibility of the deposition conditions we cleaned and outgassed the process chamber before each run and we made sure of UV lamp stability in terms of optical power and spectral emission.

\subsection{Characterization methods}

The electrical characteristics of $\mathrm{SiN}_{\mathrm{X}}: \mathrm{H}$ films have been tested by dielectric strength $\left(\mathrm{E}_{\mathrm{D}}\right)$ and breakdown $\left(\mathrm{E}_{\mathrm{BD}}\right)$ measurements on $\mathrm{Si} / \mathrm{Al} / \mathrm{SiN}: \mathrm{H} / \mathrm{Al}$ structures. We assumed the dielectric strength value as the electric field corresponding to a current of $10^{-7}$ A on a contact with a diameter of $550 \mu \mathrm{m}$. Each structure has 195 contacts. The $E_{D}$ and $E_{B D}$ values reported in the following represent the mean value of about 100 measurements executed on as many different contacts. The standard deviation has been used as an estimate of experimental errors.

The presence of porosity has been evaluated by counling "holes" and "bubbles" on $\mathrm{SiN}_{\mathrm{X}}: \mathrm{H} / \mathrm{InP}$ samples which have been evidenced by means of selective etching $\left(\mathrm{Br}: \mathrm{CH}_{3} \mathrm{COOH}=1: 100\right.$ for $\left.10^{\prime}\right)$ before and after the thermal treatment (diffusion: $\mathrm{T}=450^{\circ} \mathrm{C}$ for $16^{\prime}$ in sealed ampoule with $\mathrm{ZnAs} 2$ and $\mathrm{Zn}_{3} \mathrm{P}_{2}$ sources).

$\mathrm{Si} / \mathrm{N}$ ratio and optical gap $\left(\mathrm{E}_{\mathrm{g}}\right)$ values have been calculated from Secondary Neutral Mass Spectroscopy (SNMS) spectra and the Tauc plot method, respectively $[11,12]$.

IR analysis has been used to measure the hydrogen $(H)$ content in SiN:H/Si samples $[13,14,15]$.

Refractive index and thickness have been evaluated by ellipsometry at 632,1303 and $1535 \mathrm{~nm}$ (Plasmos SD 2300). Thickness has been also determined using a profilometer (Tencor $\alpha$-step 200). Film density $(\rho)$ has been evaluated by weighing the sample before and after the deposition. We made sure to remove the a-SiN $\mathrm{X}: \mathrm{H}$ deposited on the edges and under the substrate by masking accurately the sample surface with wax and etching it briefly in $49 \%$ hydrofluoric acid (HF). Using this technique, density measurements affected by a relative error less than $4 \%$ (calculated with the propagation law) have been obtained.

Special tests have been used to qualitatively evaluate the adhesion between dielectric/semiconductor and metalization/dielectric layers. A significant number of TiPtAu/a-SiN $\mathrm{x}: \mathrm{H} / \mathrm{InP}$ chips (chip size: $300 \mathrm{x}$ $400 \mu \mathrm{m}$ ) have been soldered with Indium in the p-side up configuration and observed using Scanning Electron Microscopy (SEM) in order to reveal eventual detachments of the TiPtAu or TiPtAu/a-SiN ${ }_{x}: \mathrm{H}$ 
layers caused by the chip cleaving. A second set of chips have been soldered in the p-side down configuration and subsequently abruptly removed using tweezers. The removed chip and the mark left on the submount have been analyzed by SEM and Energy Dispersive Spectroscopy (EDS) to evaluate the quality of the dielectric/semiconductor and metallization/dielectric adhesion.

\section{Results and discussion}

We first investigated the deposition conditions in order to obtain a-SiN:H films with good physical and structural properties. In the optimized conditions aforementioned we got a-SiN:H films with the following properties: energy gap $\left(\mathrm{E}_{\mathrm{g}}\right)=4.25 \pm 0.05 \mathrm{eV}$, refractive index $\left(\mathrm{n}_{1535}\right)$ at $1535 \mathrm{~nm}=1.85 \pm$ 0.005 , refractive index $\left(\mathrm{n}_{633}\right)$ at $633 \mathrm{~nm}=1.89 \pm 0.005, \mathrm{Si} / \mathrm{N}$ ratio $=0.8$, absence of pores and bubbles as deposited and after thermal treatment as well, density $(\rho)=2.51 \pm 0.1 \mathrm{~g} / \mathrm{cm}^{3}$. Our evaluation of hydrogen content is about $25 \%$ at. In those conditions the film growth rate is about $0.9 \mathrm{~nm} / \mathrm{min}$ up to a deposition time of 240 minutes; we then observe a slow saturation effect of the film thickness vs. the deposition time.

Forcing the $\mathrm{NH}_{3} / \mathrm{SiH}_{4}$ ratio at the limits permitted by our mass flow controllers ( $\mathrm{R}=200, \mathrm{~F}=201 \mathrm{sccm}$ ) we obtained a-SiN $: H$ films with $\mathrm{E}_{\mathrm{g}}=4.75 \mathrm{eV}, \mathrm{Si} / \mathrm{N}$ ratio $=0.75, \mathrm{n}_{1535}=1.83$. Such conditions are not reliable from the run-to-run reproducibility point of view. Hardware changes in the deposition apparatus could allow us to work with higher $\mathrm{NH}_{3} / \mathrm{SiH}_{4}$ ratios in order to have Si-rich films.

Electrical measurements performed on samples growth in the optimized conditions set yielded a $\mathrm{E}_{\mathrm{D}}$ of $5.8 \pm 0.7 \mathrm{MV} / \mathrm{cm}$ and a $E_{\mathrm{BD}}$ of $8.9 \pm 2.9 \mathrm{MV} / \mathrm{cm}$ (ligure 1 and 2).

Repeated measurements on the same contact gave us identical I/V curves. The spatial uniformity is very good as shown in figure 3. The current dependence vs. the electric field applied (E) can be explained by the Poole-Frenkel effect for high E values [16]. To our knowledge these are state of the art characteristics.

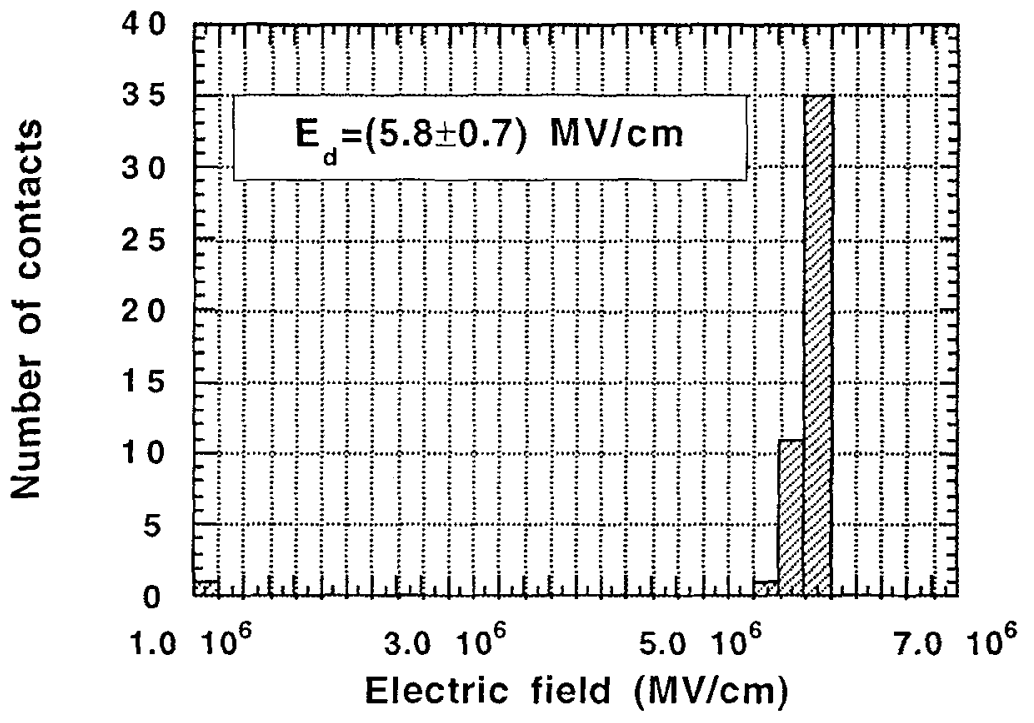

Figure 1. Histogram of the dielectric strength. 


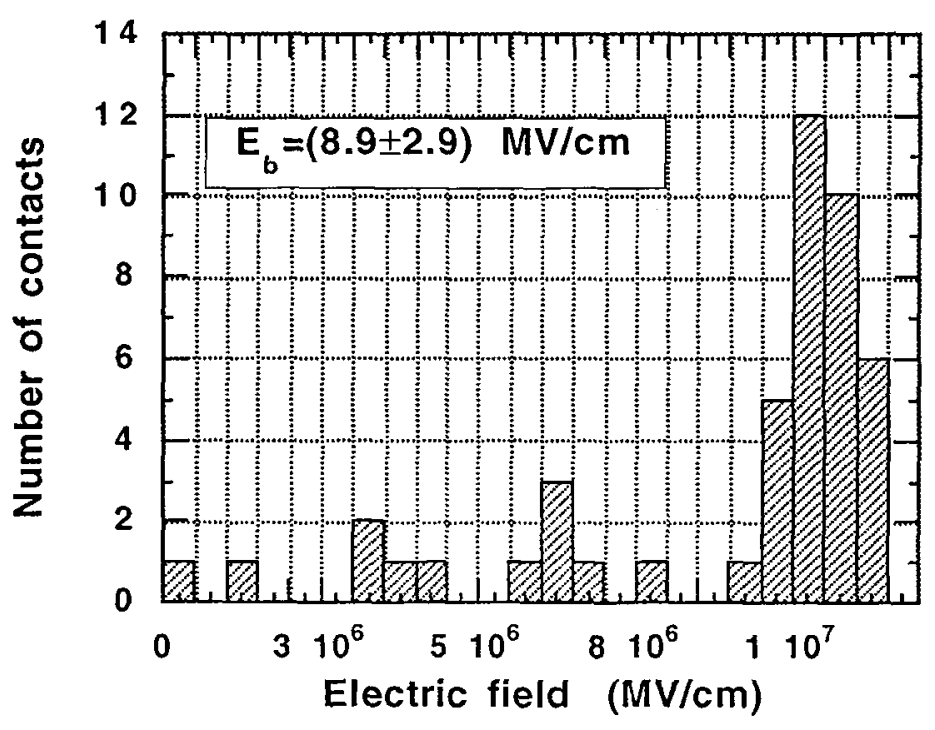

Figure 2. Histogram of dielectric breakdown

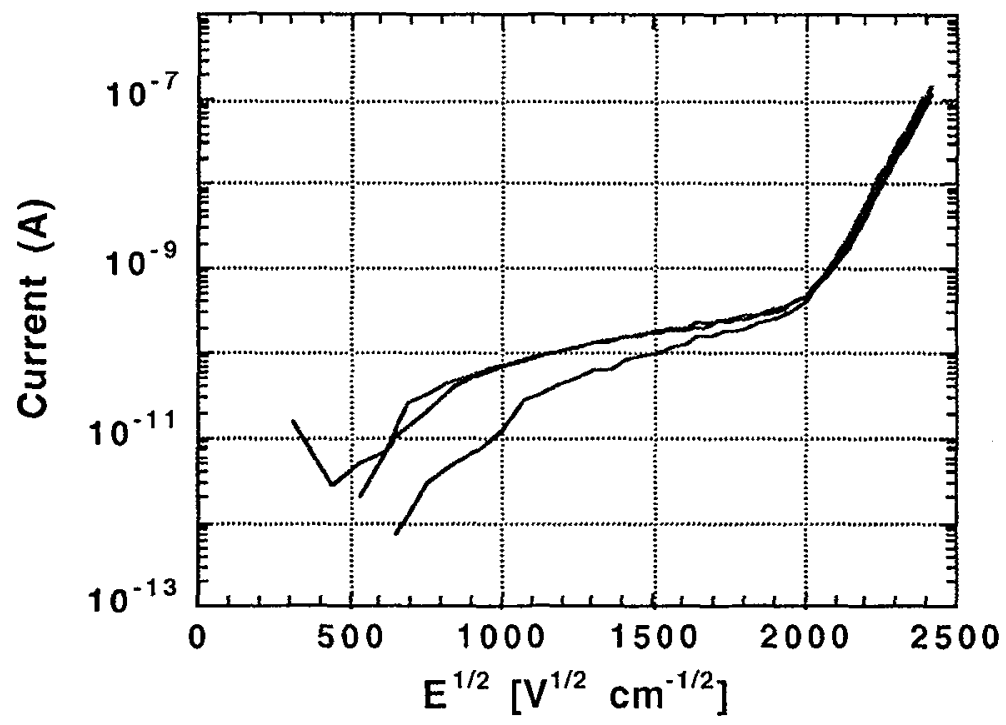

Figure 3. $\log (\mathrm{I})$ vs. applied electric field measurements corresponding to different contacts belonging to the same $\mathrm{Al} / \mathrm{a}-$ $\mathrm{SiN}_{\mathrm{X}}: \mathrm{H} / \mathrm{Al}$ sample. At high electric fields, the curves are in arreement wilh the Poole-Frenkel effect. 
The a-SiN $\mathrm{X}: \mathrm{H}$ film resistance to the mechanical treatments occurring during the device fabrication of optoclectronic devices, have been tested on TiPtAu/a-SiN $\mathrm{S}_{X}: \mathrm{H} / \mathrm{InP}$ chips hy means of the techniques described in the above. The chips soldered in the p-side up contiguration did not show any detachment of the dielectric/metallization layer. Figure 4 presents the mark on the submount left by a chip p-side down soldered after its abrupt removal. The test executed has been thought to simulate conditions much more brutal than the actual ones. A behaviour like that here reported has thus to be considered absolutely satisfactory.

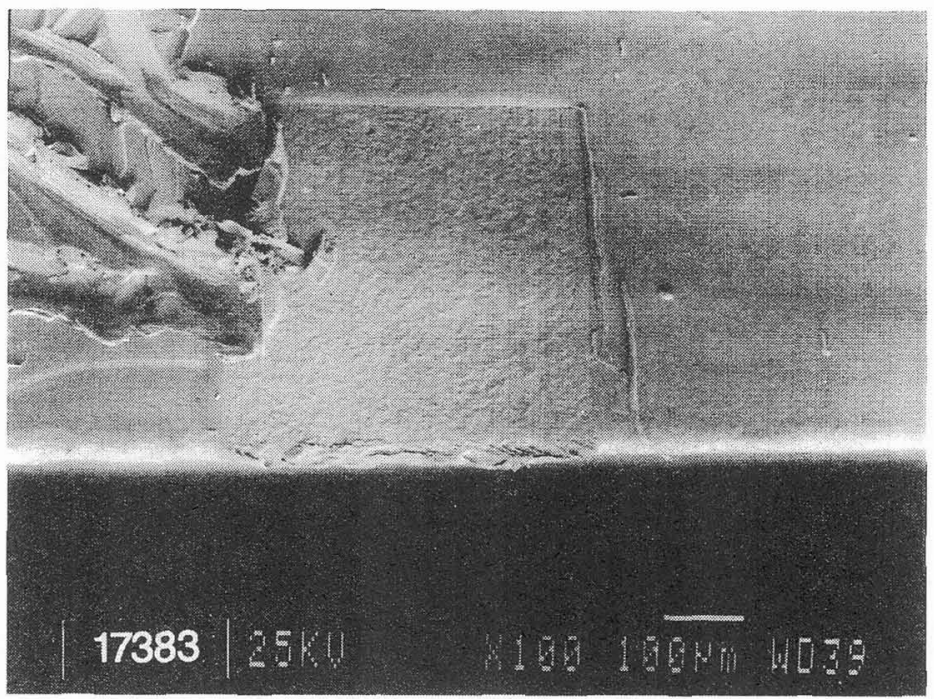

Figure 4. Matk on the submoun left by a chip p-side down soldered after its abrupe removal.

These a-SiN:H films have been proved to be suitable for process mask in III-V semiconductor technology. Figure 5 shows the adhesion of $\mathrm{SiN}$ on InP after a chemical under-etching (Saturated Bromide Water: $\mathrm{H}_{3} \mathrm{P}()_{4}: \mathrm{H}_{2} \mathrm{O}$ 2:1:15).

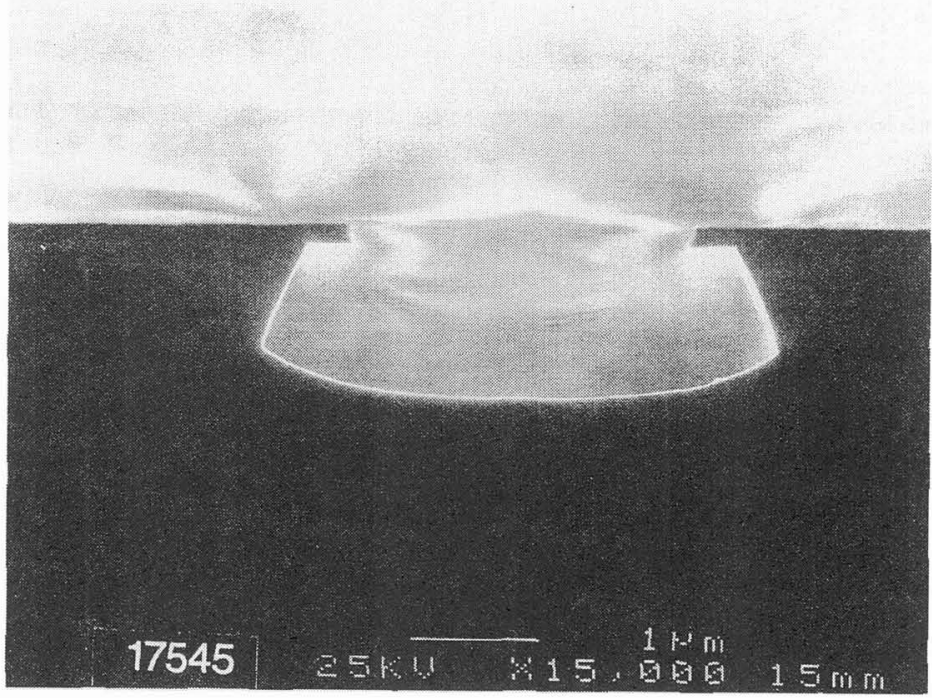

Figure 5. Adhesion of a-SiN:II on InP' after a chemical under-elching. 
A-SiN:H films have successtully been used in selective InP Metal Organic Chemical Vapour Deposition (MOCVD) regrowth on an SiN/InP structure with $1.8 \mu \mathrm{m}$ wide and $0.35 \mu \mathrm{m}$ thick ridges. Neither semiconductor polyerystalline deposition or damage have been observed on SiN surface after the regrowth process at $6000^{\circ} \mathrm{C}$.

In figgure 6 we report a Scanning Electron Microscopy (SEM) micrograph of an a-SiN:H film grown on a non-planar InP surlace. As can he clearly seen no difference exists between the dielectric thicknesses grown vertically and horizontally up to a depth of about $3 \mu \mathrm{m}$.

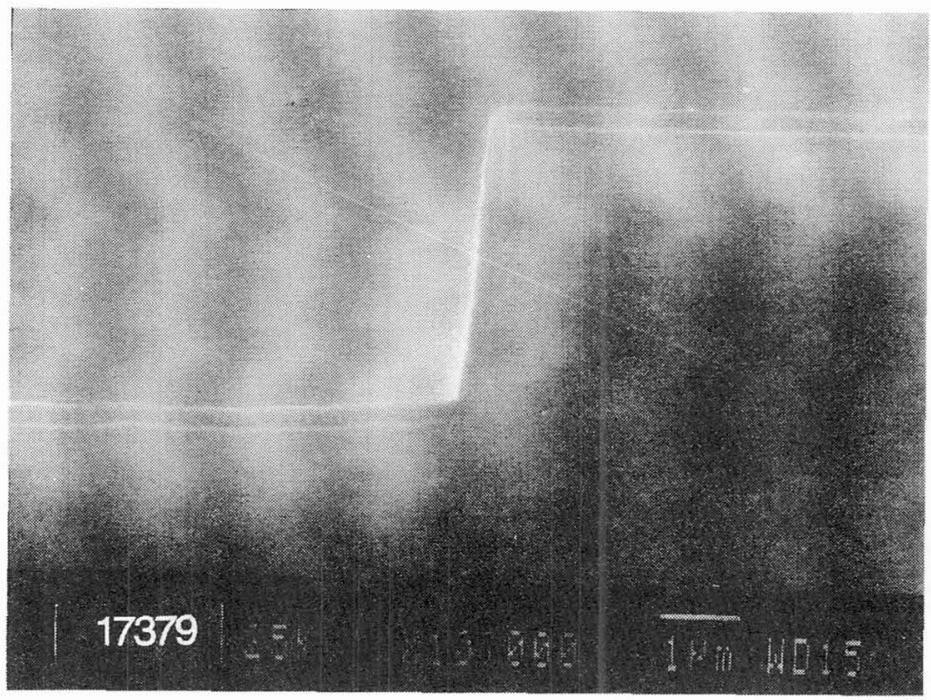

Figure 6. Scamning Electron Microscony (SEM) micrograph of an a-SiN:H film grown on a non-planar InP surlace.

We tested a-SiN:H lilms as antiretlection coatings in a semiconductor optical amplifier (SOA). Measuring the ripple value at threshold current we have been able to calculate [15] a residual facet reflectivity of $2 \%$. This value allows our films to be used as anti-reflecting coating in SOA with window facet structure [16] and for reducing coupling losses in integrated optical modulators and filters.

A measure performed hefore and after the dielectric deposition on an optical modulator did not show any increase in the dark current (hefore coating $40 \mathrm{nA}$ at $-9 \mathrm{~V}$, after coating $40 \mathrm{nA}$ at $-10 \mathrm{~V}$ ).

In the previously mentioned optimized deposition eonditions we are able to reproduce thickness, reliactive index (11535), energy gap values within $\pm 3 \%, \pm 0.005$ and $\pm 0.05 \mathrm{eV}$ respectively.

We can thus conclude that these a-SiN:H lilms can he employed in the III-V semiconductor technology for the fabrication of optoelectronic devices.

\section{Conclusions}

Optimizing the deposition conditions a-SiN:H tilms with density of $2.51 \mathrm{~g} / \mathrm{cm}^{3}$, cnergy gap of $4.25 \mathrm{eV}$, refractive index at $1535 \mathrm{~nm}$ of 1.85 , Si/N ratio of 0.8 , hydrogen percentige of about $25 \%$, absence of pores and bubbles before and after therrnal treatments, dielectric strength of $5.8 \mathrm{MV} / \mathrm{cm}$, breakdown field of $8.9 \mathrm{MV} / \mathrm{cm}$ have been obtained.

Special tests performed on structures similar to actual optoclectronic devices have shown good mechanical adhesion at the metalization/dielectric and diclectric/semiconductor interfaces.

A good step coverage has been observed up to a depth of $3 \mu \mathrm{m}$.

The use of a-SiN:H films as antirellection coatings in semiconductor optical amplifier resulted in a residual facet reflectivity of $2 \%$. 
These characteristics make such material suitable as mask for chemical etching and for selective InP MOCVD regrowth, insulating layer and antireflection coating in optoelectronic devices.

\section{Acknowledgments}

We would like to acknowledge the CSELT Optoelectronic Technologies Department for the cooperation and in particular, R. Audino, L. Boschis, L. Busso, G. Fornuto, G. Gastaldi, D. Re for the technological support and assistance in computer programming, $C$. Coriasso and $P$. Cinguino for the optical measurements, R. De Franceschi for the SEM analysis and A. Piccirillo for the useful discussions.

\section{Bibliography}

[1] Milek J.T. (ed.), Handbook of Electronic Materials, Vol. 3, Silicon Nitride for Microelectronic Applications, Part I: Preparation and Properties, (Plenum, New York, 1971).

[2] Milek J.T. (ed.), Handbook of Electronic Materials, Vol. 6, Silicon Nitride for Microelectronic Applications, Part II: Application and devices, (Plenum, New York, 1972).

[3] Hashimoto A., Kobayashi M., Kamijoh T., Tanako H. and Sakuta M., J. Electrochem. Soc. 133 (7) (1986) 1464.

[4] Chang E.Y., Cibuzar G.T., Yard T.K. and Pande K.P., Mater. Res. Soc. Symp. Proc. 126, (1988) 271.

[5] Piccirillo A. and Gobbi A.L., J. Electrochem. Soc. 137 (12) (1990) 3910.

[6] Audino R., Cannistraci F., Morello G., Valenti P., Eur. Mat. Res. Symp. Proc., Strasbourg, May 1994.

[7] Lebland F., Wang Z.Z., Flicstein J., Licoppe C., Nissim Y.I., Appl. Surf. Science 69 (1993), 198.

[8] Kumar V., Chari K.S., Agnihotri O.P., Thin Solid Films, 232 (1993), 47.

[9] Lemiti M., Audisio S., Dupay J.C., Balland B., J. of Non-Cryst. Solids, 144 (1992), 261.

[10] Shacham-Diamand Y., Chuh T., Oldham W.G., Solid-State Electron., 30 (1987) 227.

[11] Rand M. J. and Wonsilder D. R., J. Electrochem. Soc., 125 (1) (1978) 99.

[12] Tauc J., Amorphous and liquid semiconductor, (Plenum Press, London and New York, 1974).

[13] Campmany I., Bertran E., Andújar J.L., Canillas A., López-Villegas J.M., Morante J.R., Mat. Res.

Soc. Symp. Proc. 258 (1992).

[14] Hasegawa S., He L., Amano Y., Inokuma T., Phys. Rev. B 48 (8), (1993), 5315.

[15] Manfredotti C., Fizzotti F., Boero M., Pastorino P., Polesello P., Vittone E., Phys. Rev. B 50 (24), (1989), 18046.

[16] Sze S., Physics of semiconductor devices, II edition, (Wiley Interscience, New York 1981).

[17] Saitoh T., Mukai T., J. of Lightwave Tech., 6 (11) (1988), 1656.

[18] Cha I., Kitamura M., Honmou H., Mito I., Electronics Lett., 25 (18), (1989), 1241. 